\section{Gold Catalysis Highlights at EuropaCatVl, Innsbruck, Austria, 31 August - 4 September 2003}

This proved to be a lively and stimulating meeting with over 1,200 participants. There were 89 oral presentations and over 1,000 posters. Six of the talks had gold catalysis as a principal theme and 24 of the posters included gold in the title. It was interesting that gold was mentioned as a "hot topic' by one of the chairmen and the new interest in gold catalysis was also indicated by other speakers from both academia and industry. Catalysis by gold was thus confirmed as being a significant part of the catalysis scene $(1,2)$. A greater understanding of the mechanistic pathways operating during the reactions catalysed by gold and better definition of the optimal reaction conditions will lead to yet more new discoveries and applications.

The six talks principally focused on gold had the following titles:

Partial Oxidation of Polyols on Nanoscale Gold Catalysts, by A. Martin, H. Bernt, I. Pitsch and A. Dittmar, Institut für Angewante Chemie Berlin-Aldershof e.V., Berlin, Germany

The Active Oxygen Species for Oxidation using Gold Catalysts, by Nianxue Song, Christopher D. Jones, Jonathan K. Bartley, Stuart H. Taylor and Graham J. Hutchings, Department of Chemistry, Cardiff University, UK

Electronic Structure of Gold Particles in $\mathrm{Au} / \mathrm{TiO}_{2}$ Catalysts: In-situ X-Ray Absorption Fine Structure (XAFS) Studies, by E.A Willneff and S.L.M. Schroeder, UMIST, Manchester, UK, and N Weiher, FU Berlin, Germany

CO Selective Oxidation in Excess of $\mathrm{H}_{2}$ on Gold and Copper Catalysts Supported on $\mathrm{ZnO}$ and $\mathrm{TiO}_{2}$ : a Comparative FTIR and Quadruple Mass Spectrometry Study, by M. Manzoli, A. Chiorino and F. Boccuzzi, University of Torino, Italy

The Beneficial Effect of Adding Base Metal Oxides to Noble Metal Catalysts on Reactions Relevant to Air
Pollution Abatement, by B.E. Nieuwenhuys, A.C. Gluhoi, R.J.H. Grisel, S.D. Lin and C.J. Weststrate, Leiden University, The Netherlands

Low Temperature CO Oxidation on Metal Oxide Supported Gold Catalysts, by Jürgen Behm, University of Ulm, Germany

Professor Nieuwenhuys emphasized the interesting and often advantageous activity profiles of gold and gold alloy catalysts in a range of applications such as NOx reduction, the PROX reaction (removal of CO from hydrogen streams), ammonia oxidation and $\mathrm{CO}$ oxidation, particularly when a mixed oxide support is used, and re-named his talk 'A Golden Future for Gold Catalysis'. In addition to the above talks, where results were described which increase our understanding of the mechanism of gold catalysis and indicate a range of potential applications, very interesting durability data on gold catalysts was presented by Professor A.K. Datye, University of New Mexico, Albuquerque, USA, who has demonstrated that alumina-supported gold catalysts with $2 \mathrm{~nm}$ gold particles are stable at $600^{\circ} \mathrm{C}$ for $96 \mathrm{~h}$ if there is no chloride present in the catalyst.

Amongst the posters were the following:

Preparation of Gold Catalysts for the Preferential Oxidation of $\mathrm{CO}$ in the Presence of Hydrogen (PROX), by Attila Wootsch, Claude Descorme and Daniel Duprez, LACCO-UMR, Université de Poitiers, France and Institute of Isotopes and Surface Chemistry, Budapest, Hungary

Selective Oxidation of $\mathrm{CO}$ in Hydrogen with Gold Supported on Ceria Oxide Catalysts under Fuel Cell Operating Conditions, by G. Panzera, A.Donato, V. Modafferi, S. Candamano and P.L. Antonucci, University of Reggio Calabria, Italy

Influence on WGS Activity of Preparative Procedure used for Au/Ceria Catalyst, by T. Tabakova, F. Boccuzzi, M. Manzoli and D. Andreeva, Institute of Catalysis, Sofia, Bulgaria and University of Torino, Italy

The Redox of Gold Deposited on Ceria and CeriaZirconia and its Implication in $\mathrm{CO} / \mathrm{H}_{2} \mathrm{O}$ Activation for the WGS, by M. Vicario, C. de Leitenburg, J. Llorca, G. Dolcetti and A. Trovarelli, University of Udine, Italy and University of Barcelona, Spain

Real Structure of Gold Catalysts and Identification of their Active Sites in the Selective Hydrogenation of Acrolein, by Peter Claus, H. Hofmeister, Ch. Mohr and J. Radnik, Darmstadt University of Technology, Max-Planck Institute, Weinberg and Institute of Applied Chemistry, Berlin, Germany Hydrogenation of Crotonaldehyde by Nanoparticles of Gold Supported on $\mathrm{TiO}_{2}$, by Rodolfo Zanella, Suzanne Giorgio, Catherine Louis and Raymonde Touroude, CNRS, Université Paris, Marseille Cedex and Strasbourg Cedex, France Interaction and Reaction of $\mathrm{CO}$ and NO on Supported Gold Catalyst, by F. Solymosi, T. Bansagi and T.S. Zakar, Institute of Solid State and Radiochemistry, Szeged, Hungary 


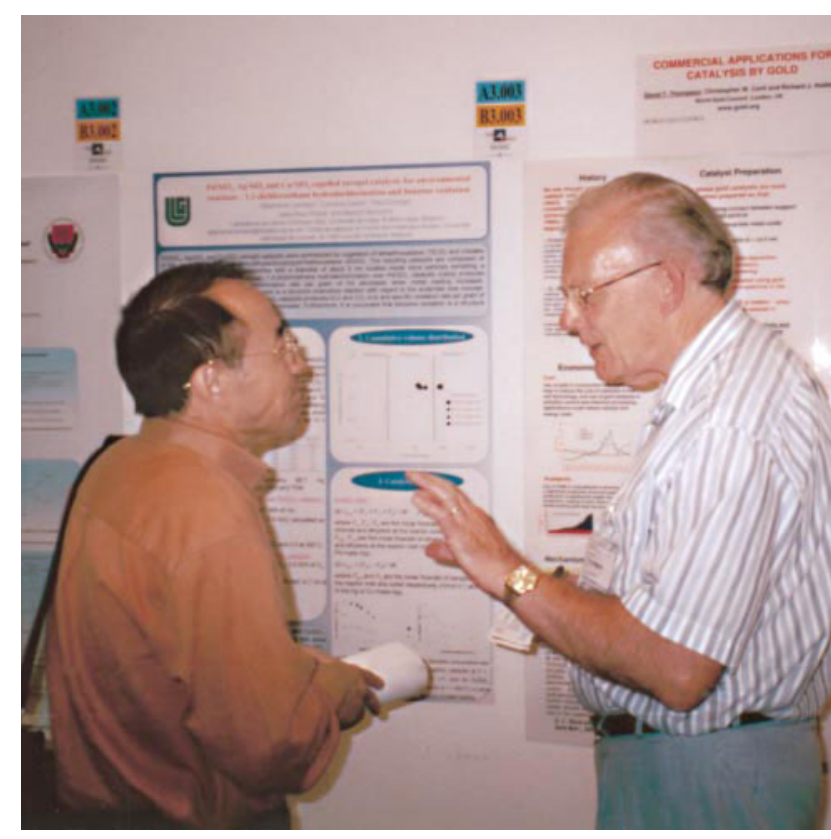

Catalytic and Non-Catalytic CO Oxidation on $\mathrm{Au} / \mathrm{TiO}_{2}$ Catalysts, by J.M.C. Soares and M. Bowker, University of Cardiff, UK

AuPd/TiO 2 Bimetallic Nanoparticles: XRD, TEM, in situ EXAFS Studies and Catalytic Activity in CO Oxidation, by K. Frey, A. Beck, A. Horvath, Zs. Koppany, G. Stefler, D. Bazin and L. Guczi, Institute of Isotope and Surface Chemistry, Budapest, Hungary and LURE, Université, Paris, Orsay, France

Oxidation of $\mathrm{CO}$ and $\mathrm{C}_{3}$ Hydrocarbons on Gold Dispersed on Oxide Supports, by M. Grasior, B. Grzybowska, K. Samson, M. Ruszel and J. Haber, Institute of Catalysis and Surface Chemistry, Polish Academy of Sciences, Krakow, Poland

Gold-Catalysed Gas Phase Oxidation of Primary and Secondary Alcohols, by Serena Biella and Michele Rossi, University of Milan, Italy

Selective Oxidation of Glycerol with Gold on Carbon Catalyst: an Insight into the Reaction Pathway, by Laura Prati and Francesco Porta, University of Milan, Italy

Effect of Gold on the Hydrodesulfurization Activity of Supported Platinum Catalysts, by A.M. Venezia, V. La
Parola, V. Nicoli and G. Deganello, ISMN-CNR, Palermo and University of Palermo, Italy

Application of XPS to Study Adsorption of Activated Oxygen on a Gold Surface, by A.I. Boronin, A.I. Stadnichenko, E.M. Pazhetnov and S.V. Koscheev, Novosibirsk, Russia

Structural Stability of Iron Oxide Supported Gold Model Catalysts, by R. Meyer, Sh. K. Shaikhutdinov and H.J. Freund, Fritz-Haber-Institut, Berlin, Germany

Design of Reductive Nanogold Formation Routes and Catalysis by Stabilized Gold Particles, by K. Mallick, A. Venugopal, J. Aluha, T. Magadzu and M.S. Scurrell, University of Witwatersrand, South Africa

Controlling Gold Nanoparticle Dispersion by Modification of Activated Carbon Fibres used as a Catalyst Support, by D.A. Bulushev, L. Kiwi-Minsker, I. Yuranov, E.I. Suvorova, P.A. Buffat and A. Renken, Swiss Federal Institute of Technology, Lausanne, Switzerland

In a World Gold Council poster entitled 'Commercial Applications for Catalysis by Gold' by D.T. Thompson, C.W. Corti and R.J. Holliday, the potential of the recent advances in gold catalysis for applications in pollution control, fuel cells and chemical processing were highlighted and the commercial benefits of using gold in these areas rationalized. Current developments in heterogeneous catalysis in both the gas and liquid phase were described and progress in homogeneous catalysis indicated. The various useful methods of preparation were highlighted and an approach suggested to gain a mechanistic understanding of the reactions, many of which take place under mild conditions. Interest in the work described was expressed by both academic and industrial delegates.

David Thompson

\section{References}

1 D.T. Thompson, Gold Bull., 2003, 36, 109

2 C.W. Corti, R.J. Holliday and D.T. Thompson, Gold Bull., 2002, 35, 111 